\title{
Radical prostatectomy for high-risk prostate cancer I Opinion: NO
}

\author{
Saum Ghodoussipour ${ }^{1}$, Giovanni Enrico Cacciamani ${ }^{1}$, Andre Luis de Castro Abreu ${ }^{1}$ \\ ${ }^{1}$ USC Institute of Urology and Catherine \& Joseph Aresty Department of Urology, University of Southern Cali- \\ fornia, Los Angeles, CA, USA.
}

Keywords: Prostatic Neoplasms; Prostatectomy; Radiotherapy

\section{BACKGROUND}

Prostate cancer (PC) is the most common solid malignancy in men. In 2019, there are expected to be 174,000 new diagnoses in the United States with 31,000 patients ultimately succumbing to their disease (1). Those with more aggressive disease are at a greater risk of local treatment failure and death (2), thus emphasis on the appropriate management for the subset of patients with high risk PC (HRPC) is paramount.

Current guideline recommendations for patients with HRPC include radical prostatectomy (RP), external beam radiotherapy (EBRT) with androgen deprivation therapy (ADT) or EBRT plus brachytherapy (BT) and ADT (3-6). Each guideline panel separately defines the criteria that place patients at higher risk of adverse outcomes. These criteria include a combination of preoperative prostate specific antigen (PSA), biopsy Gleason score and clinical stage (Table-1). Herein, it is our goal to highlight the differences in outcomes amongst these treatment options, the heterogeneity that exists within the HRPC category and to show where the evidence for treatment of HRPC with surgery is lacking.

\section{A role for definitive treatment}

In 2012, results from the PIVOT trial exposed the heterogeneity of PC. Men with low risk disease appeared to have long-term disease specific survival whether or not they underwent surgery or watchful waiting. However, those with higher risk disease were at greater risk of developing bone metastases or death without surgery (7). The SPCG-4 trial similarly found a survival benefit with surgery over watchful waiting in men with localized PC and HR features (8). Likewise, studies of radiotherapy have shown a benefit to radiotherapy plus ADT vs. ADT alone in localized HRPC (9-11). As such, local therapy with surgery or radiation is needed in HRPC but the optimal treatment remains controversial.

\section{Surgery as primary treatment}

Urologists have historically been cautious with surgery for patients with HRPC. While the era of aborted procedures for gross nodal involvement has passed (12), concerns exist over extraprostatic disease leading to treatment failure and need for adjuvant therapies. This coupled with risks of surgery and postoperative functional outcomes have allowed Radiation 
Table 1 - High Risk Prostate Cancer definition criteria according to different Guidelines panels.

\begin{tabular}{|c|c|c|c|}
\hline & \multicolumn{2}{|c|}{ High-Risk PC } & Very High-Risk PC \\
\hline & Localized & Non Localized & \\
\hline \multirow[t]{2}{*}{$\begin{array}{l}\text { EAU/ ESTRO/ESUR/SIOG } \\
\text { Guidelines }\end{array}$} & $\begin{array}{l}\text { PSA }>20 \mathrm{ng} / \mathrm{ml} \text { or GS }>7 \text { ( } \\
\text { ISUP Grade 4/5) or cT2C }\end{array}$ & $\begin{array}{c}\text { any PSA any GS (any GS grade) } \\
\text { cT3-4 or cN+ }\end{array}$ & Not defined \\
\hline & \multicolumn{2}{|c|}{ Localized } & \\
\hline \multirow{2}{*}{$\begin{array}{l}\text { AUA/ASTRO/SUO } \\
\text { Guidelines }\end{array}$} & $\mathrm{PSA} \geq 20 \mathrm{ng} / \mathrm{ml}$ or GS $>$ & ISUP Grade $4 / 5$ ) or $\geq c T 3$ & Not defined \\
\hline & \multicolumn{2}{|c|}{ Localized } & Localized \\
\hline NCCN Guidelines & \multicolumn{2}{|c|}{ PSA > 20 ng/ml or GS > 7 ( ISUP Grade 4/5) or cT3a } & $\begin{array}{c}\text { cT3b-cT4 or Primary } \\
\text { Gleason pattern } 5 \\
\text { or }>4 \text { cores with } \\
\text { GS }>7\end{array}$ \\
\hline
\end{tabular}

EAU = European Association of Urology; ESTRO = European Society for Radiotherapy \& Oncology; SIOG = International Society of Geriatric Oncology; $\mathbf{A U A}=$ American Urological Association; ASTRO = American Society for Radiation Oncology; $\mathbf{S U O}=$ Society of Urologic Oncology; $\mathbf{N C C N}=$ National Comprehensive Cancer Network. PSA = Prostate Specific Antigen; GS = Gleason score; ISUP = International Society of Urological Pathologists.

Oncologists to establish dominance in the primary management of HRPC, with EBRT $+\mathrm{ADT}$ or EBRT + BT + ADT as the only recommendations with Category 1 evidence in the NCCN guidelines (3). Despite this, the use of surgery for HRPC is on the rise (13) and owed mostly to retrospective series that show prostate cancer specific survival (PCSS) rates of $>90 \%$ (14-21). However, a deeper dive into this literature reveals concerning patterns. Namely, the studies are limited by bias inherent to their retrospective design, a prevalent use of adjuvant therapy and heterogeneous outcomes amongst men in the HR group. In a study by Loeb et al., 175 men underwent RP for HRPC with 10-year PCSS of 92\%. However, biochemical recurrence-free survival (BCRFS) was 68\%, metastasis-free survival (MFS) was $84 \%$ and $29 \%$ of all patients required some type of hormonal therapy (14). Briganti et al. reviewed 1,366 patients with HRPC who underwent RP at 8 European centers. Only $37 \%$ of the patients had specimen-confined disease at final pathology, but 10-year PCSS was significantly higher in this group vs. those with extraprostatic disease (98\% vs. $88 \%, p<0.0001$ ) as was BCRFS (66\% vs $47 \%$, $\mathrm{p}<0.0001)$. Adjuvant therapy with either ADT or RT was used in $48 \%$ of all patients; $66 \%$ with extraprostatic disease and 17\% with specimen- confined disease (15). A retrospective review by Ward et al. of 5,652 men who underwent $\mathrm{RP}$ at a single institution found 842 who had surgery for locally advanced (cT3) disease. PCSS for the entire cohort at 10 years was $90 \%$ but $78 \%$ of those with pT3 disease received adjuvant therapy, highlighting a risk of local failure and need for multimodal therapy with primary surgery (17). Spahn et al. reported on 550 patients with preoperative HRPC and found an 8-year PCSS of 88\%. The importance of stage and surgical margins was revealed as those with pT3a disease or $\mathrm{pT} 3 \mathrm{~b}$ with negative margins had a PCSS of 92\% while those with pT3b disease and positive bladder neck margins had a 5-year PCSS of $60 \%$ (20). A review by Djaladat et al. of 358 patients with Gleason 8-10 disease after RP, found significantly better 5-year BCRFS and clinical recurrence free survival in those with Gleason 8 vs. Gleason 9-10 disease (75.5\% vs. $71.2 \%, p=0.01$ and $94 \%$ vs $86.2 \%, p=0.02$, respectively) (22). Yossepowitch et al explored the divergent outcomes in men considered to have HRPC. They studied 5,960 men who underwent RP to determine how accurately common used definitions of HR disease can predict need for adjuvant therapy, risk of metastases and death from PC. They identified 8 different high-risk subsets with freedom 
from secondary therapies ranging from 35$76 \%$ and incidence of death from prostate cancer ranging from 3-11\% (18).

Clearly, some patients with HRPC do well after surgery but should it be offered to all men with HRPC? A critical appraisal of the studies above suggests that surgical benefit required adjuvant treatment and was greatest in men with lower or more intermediate risk features. Thus, the answer to the question of ideal treatment options requires a contemporary look at risk groupings.

\section{Defining "true" high-risk patients}

In 2012, Pierorazio et al. sought to identify preoperative characteristics that would predict unfavorable pathology and clinical outcomes after RP. They examined 842 men with Gleason score 8-10 on preoperative biopsy. Unfavorable final pathology (defined as Gleason 8-10 disease and pT3b or N1 disease) was found in $22 \%$ of men. Those with unfavorable pathology had worse 10-year BCRFS (4.3\% vs. 31\%) and half received adjuvant therapy. Despite adjuvant treatment, they still had worse MFS (29.1\% vs. $60.9 \%$ ) and PCSS (52.3\% vs $74.7 \%$ ) when compared to those with favorable pathology. On multivariate logistic regression analysis, a PSA $>10 \mathrm{ng} / \mathrm{mL}$, cT2b or higher, Gleason 9 or 10, increasing number of cores positive and $>50 \%$ core involvement were predictive of unfavorable pathology (23). A follow up study from the same institution by Sundi et al proposed a sub-stratification of men with HRPC into two separate groups; HR defined per NCCN guidelines as Gleason 8-10 on biopsy, PSA $>20 \mathrm{ng} /$ $\mathrm{mL}$ or clinical stage $\geq \mathrm{T} 3$ and very high-risk (VHR), defined as primary Gleason pattern 5 on biopsy, $\geq 5$ cores with Gleason 8-10 disease or multiple NCCN high-risk features. Of 753 men with NCCN HR disease, 15.1\% were found to have VHR disease. These men had significantly worse 10 - year MFS (37\% vs $78 \%$ ) and PCSS (62\% vs 90\%) (24).

These findings prompted an update to the NCCN guidelines in 2015, which now distinguish between HR ( $\geq$ CT3a or Gleason 8-10 or preoperative PSA $>20 \mathrm{ng} / \mathrm{mL}$ ) and VHR PC (cT3B or greater, primary Gleason pattern 5, or 5 or more cores with Gleason 8-10) (3).

The European Urological Association (EAU) discriminates between localized and non- localized HRPC. The first is defined as PSA $>20 \mathrm{ng} / \mathrm{mL}$ or Gleason $>7$ (International Society of Urological Pathologists, ISUP Grade $4 / 5$ ) or cT2c, while the second includes cT3a-cT4 with any PSA and any GS (any ISUP score) (4). The America Urological Association defines the HRPC as any patient with PSA $\geq$ $20 \mathrm{ng} / \mathrm{mL}$ or Gleason score $>7$ (ISUP Grade $4 / 5)$ or cT3, including only the non-localized diseases (Table-1) $(5,6)$.

The incorporation of VHR criteria into the NCCN guidelines was validated by Pompe et al. who performed a retrospective evaluation of 1,369 VHR cases compared to 2,672 HR ones. Those with VHR disease had higher rates of positive margins (43\% vs 32.8\%, $\mathrm{p}<0.001)$ and positive lymph nodes $(40 \%$ vs $23.9 \%, p<0.001)$ than those with HR disease. Biochemical recurrence occurred within 12 months in 53.7\% of those with VHR disease. These patients received adjuvant therapy in $15.2 \%$ and salvage in $42 \%$ of cases. BCRFS at 8 years was $25.4 \%$ in the VHR group and $43.1 \%$ in the HR group ( $\mathrm{p}<0.001)$. Similarly worse differences were seen in 8-year MFS (71.5\% vs $86.1 \%, \mathrm{p}<0.001)$ and PCSS $(76 \%$ vs $83.7 \%, \mathrm{p}<0.001)$ in the VHR compared to HR groups, respectively (25).

A recent collaborative study from 3 tertiary centers examined the outcomes after surgery in patients with HR vs VHR disease as defined by the prior report from Sundi et al (26). They included 1,981 men with HRPC and 602 with VHR disease. The rates of positive margins and nodal metastases were significantly greater in the VHR group compared to the HR group (37\% vs $25 \%$ and $37 \%$ vs $15 \%$, respectively, $\mathrm{p}<0.001)$. The development of metastases and death from prostate cancer were also significantly higher for those with VHR vs HR disease (HR 2.78, 95\% CI 2.083.72 and 6.77 95\% CI 2.91-15.7, respectively). Overall, 34 men died from PC and they were more likely to have met VHR vs HR criteria (76\% vs $24 \%, \mathrm{p}<0.001$ ).

If the summative conclusion from these studies is that certain men with truly (very) 
HR disease do worse after surgery, do they also do worse after radiation therapy? Two recent reports give conflicting evidence. Narang et al compared 288 patients with HRPC as defined by the NCCN guidelines and 99 with VHR disease as defined by Sundi et al (27). All men received definitive radiation therapy by a single provider and they found that men in the VHR group did significantly worse. Men with VHR as compared to HR disease had greater biochemical failure ( $54 \%$ vs $35 \%, p<0.001$ ), distant metastases ( $34.9 \%$ vs $13.4 \%, \mathrm{p}<0.001$ ) and death from PC (18.5\% vs 5.9\%, $\mathrm{p}<0.001)$. However, the median radiation dose received by all patients was 70.2Gy, which is considered sub-standard for men with HR disease given the results of a randomized trial showing the benefits of dose escalated RT (28). Only $75 \%$ of VHR and $61 \%$ of HR patients received neoadjuvant, concurrent and adjuvant ADT as is recommended by guidelines (3). A more recent report by Saad et al compared 103 patients with VHR and 100 with HR disease per NCCN guidelines. The dose to the prostate was 78-82Gy, to the pelvic lymph nodes was 46-50 Gy and duration of ADT ranged 6 months to 2 years. They found no statistically significant difference in 4- year BCRFS (85\% vs 92\%), MFS (87\% vs 93\%) and PCSS (98\% vs 100\%). However, distant metastases were more common in the VHR group and a $P S A \geq 40 n g / m L$ was predictive of biochemical recurrence (HR 3.75) and distant metastases (HR 3.25) (29).

\section{Surgery vs. radiation}

The literature comparing surgery vs radiation in HRPC lacks direct comparison with randomized trials. Several retrospective studies have been performed. While a simple vote count of those favoring surgery or radiation does not provide conclusion, some inferences can be made. In a study of 7,538 men with localized PC in the CAPSURE database, Cooperberg et al found a greater risk of death from PC with EBRT vs RP (HR 3.22, 95\% CI 2.16-4.81 vs 2.1 95\% CI 1.50 -3.24). This difference was greatest in those men with HRPC (30). While not studying HRPC on its own, Zelefsky et al reported on men with cT1-T3a PC and found that RP had a lower risk of metastases and death from PC as compared to EBRT (31). In a study of men with HRPC, Boorjian et al compared 1,238 men after had RP, 344 with EBRT + ADT and 265 with ADT alone and found similar 10-year PCSS among all groups (92\%, 92\% and 88\%, respectively; $p=0.06$ ). There was no difference in risk of metastases or death from prostate cancer but the risk of all causes mortality was greater after EBRT + ADT vs RP (HR 1.60, 95\% CI 1.25-2.05) (32). Kishan et al performed a multi-center review of 487 patients with Gleason 9-10 disease on biopsy and compared 230 with EBRT, 87 with EBRT + BT, and 170 with RP. Local salvage was required in $49 \%$ of RP patients not receiving adjuvant therapy, 0.9\% of EBRT patients and $1.2 \%$ of EBRT + BT patients $(\mathrm{p}<0.0001)$. The 10-year MFS was higher for EBRT + BT compared to either EBRT or RP $(89.8 \%$ vs $66.7 \%$ vs $61.5 \%$, respectively, $\mathrm{p}<0.01$ for both $\mathrm{EBRT}+\mathrm{BT}$ vs EBRT and EBRT + BT vs RP) but 10-year PCSS was similar amongst all (80.5\% for EBRT, 88.1\% for EBRT + BT, and 78.5\% for RP, $p>0.1$ ). However, a subset analysis of those who received dose escalated radiotherapy showed a significant improvement in PCSS (HR 0.93, 95\%CI 0.87-0.99) (33).

The concept of a survival advantage with a dose-escalated boost of radiotherapy was furthered by Kalbasi et al who performed a retrospective analysis of 13,538 men from the National Cancer Database (NCDB). They compared dose-escalated vs standard dose EBRT for men with intermediate or HRPC. Dose escalation was associated with a survival advantage in the HR group (HR 0.82, 95\% CI 0.78-0.85) and every 2 Gy increase lead to a $6.3 \%$ reduction in the risk of death (34). Moreover, results of the ASCENDE-RT trial have strengthened evidence for the role of BT in men with HRPC. In this study, all men with HRPC received 12 months of ADT and EBRT with 46Gy followed by either a dose-escalated boost to 78Gy or a low-dose-rate brachytherapy boost. They found that men randomized to BT experienced a 2-fold decrease in risk of biochemical recurrence as compared to those who received a boost with EBRT (HR 2.04, p=0.004) (35). There have sin- 
ce been conflicting reports from the NCDB on the role of EBRT + BT boost as compared to RP $(36,37)$, but they are limited by the inherent lack of granularity in the database where disease specific survival and progression are not available and true rates of ADT use and radiation dosage are unclear. In a recent report by Tilki et al, 639 men with Gleason 9-10 disease who had either RP $(n=559)$ or EBRT + ADT + BT $(n=80)$ were compared. There was no difference in risk of death from prostate cancer amongst the two groups (HR 1.33, 95\%CI 0.49-3.64), but $15.7 \%$ of RP patients received adjuvant EBRT, 8.8\% received ADT and 8.9\% received both. This suggests that an equivalent survival in primary surgery vs primary radiotherapy comes from the adjuvant treatment surgical patients receive (38). Concerns over increased side effects with BT are real (39), but the radiotherapy literature has put forth new efforts to decrease morbidity while still providing what appears to be an effective treatment boost. An ongoing trial investigating the role of focal dose escalation to MRI targeted lesions has shown no increase in toxicity when compared to standard radiation doses (40).

\section{CONCLUSIONS}

Several guideline-approved options exist in the management of HRPC. While data indicate that local treatment is needed, the appropriate role of surgery vs radiation remains less clear. In consideration of efficacy, RP certainly seems to be efficacious in a subset of patients with HRPC. However, retrospective series suggests the benefit is greatest in patients with lower risk disease. In the VHR group alone, RP is plagued by local failure and radiotherapy by distant failure. For this reason, trials are underway to investigate the added benefit of systemic therapy with radiotherapy in localized disease (41) and greater efforts at improving local control with surgery are needed. Side effects need to be considered as well. While radiotherapy comes with greater irritative voiding symptoms, surgery is associated with decrease in sexual function and urinary continence when compared to EBRT (42). Again, the impetus is on Urologists to improve these outcomes without sacrificing local control of disease. As it stands, the surgical management of HRPC is a multimodal one where patients should expect the use of adjuvant therapies such as radiation or ADT. The conflicting results of several retrospective series merit further investigation with clinical trials (43).

\section{CONFLICT OF INTEREST}

None declared.

\section{REFERENCES}

1. Siegel RL, Miller KD, Jemal A. Cancer statistics, 2019. CA Cancer J Clin. 2019;69:7-34.

2. D'Amico AV, Chen MH, Catalona WJ, Sun L, Roehl KA, Moul JW. Prostate cancer-specific mortality after radical prostatectomy or external beam radiation therapy in men with 1 or more high-risk factors. Cancer. 2007;110:56-61.

3. Carroll PH, Mohler JL. NCCN Guidelines Updates: Prostate Cancer and Prostate Cancer Early Detection. J Natl Compr Canc Netw. 2018;16:620-3.

4. N. Mottet (Chair), R.C.N.v.d.B., E. Briers (Patient Representative), L. Bourke, P. Cornford (Vice- chair), M. De Santis, et al. European Association of Urology: Guidelines on prostate cancer 2018. Available at $<$ https://uroweb.org/guideline/prostate-cancer>.

5. Sanda MG, Cadeddu JA, Kirkby E, Chen RC, Crispino T, Fontanarosa J, et al. Clinically Localized Prostate Cancer: AUA/ASTRO/SUO Guideline. Part II: Recommended Approaches and Details of Specific Care Options. J Urol. 2018;199:990-7.

6. Sanda MG, Cadeddu JA, Kirkby E, Chen RC, Crispino T, Fontanarosa J, et al. Clinically Localized Prostate Cancer: AUA/ASTRO/SUO Guideline. Part I: Risk Stratification, Shared Decision Making, and Care Options. J Urol. 2018;199:683-90.

7. Wilt TJ, Brawer MK, Jones KM, Barry MJ, Aronson WJ, Fox S, et al. Radical prostatectomy versus observation for localized prostate cancer. N Engl J Med. 2012;367:203-13. Erratum in: N Engl J Med. 2012;367:582.

8. Bill-Axelson A, Holmberg L, Garmo H, Rider JR, Taari $\mathrm{K}$, Busch $\mathrm{C}$, et al. Radical prostatectomy or watchful waiting in early prostate cancer. $\mathrm{N}$ Engl $\mathrm{J}$ Med. 2014;370:932-42. 
9. Brundage $M$, Sydes MR, Parulekar WR, Warde $P$, Cowan R, Bezjak A, et al. Impact of Radiotherapy When Added to Androgen-Deprivation Therapy for Locally Advanced Prostate Cancer: Long-Term Quality-ofLife Outcomes From the NCIC CTG PR3/MRC PR07 Randomized Trial. J Clin Oncol. 2015;33:2151-7.

10. Bolla M, Van Tienhoven G, Warde P, Dubois JB, Mirimanoff RO, Storme G, et al. External irradiation with or without long-term androgen suppression for prostate cancer with high metastatic risk: 10-year results of an EORTC randomised study. Lancet Oncol. 2010;11:1066-73.

11. James ND, Spears MR, Clarke NW, Dearnaley DP, Mason MD, Parker CC, et al. Failure-Free Survival and Radiotherapy in Patients With Newly Diagnosed Nonmetastatic Prostate Cancer: Data From Patients in the Control Arm of the STAMPEDE Trial. JAMA Oncol. 2016;2:348-57. Erratum in: JAMA Oncol. 2016;2:279.

12. Boorjian SA, Thompson RH, Siddiqui S, Bagniewski S, Bergstralh EJ, Karnes RJ, et al. Long-term outcome after radical prostatectomy for patients with lymph node positive prostate cancer in the prostate specific antigen era. J Urol. 2007;178(3 Pt 1):864-70.

13. Pooli A, Salmasi A, Faiena I, Lenis AT, Johnson DC, Lebacle $C$, et al. Variation in surgical treatment patterns for patients with prostate cancer in the United States: Do patients in academic hospitals fare better? Urol Oncol. 2019;37:63-70.

14. Loeb S, Schaeffer EM, Trock BJ, Epstein JI, Humphreys EB, Walsh PC. What are the outcomes of radical prostatectomy for high-risk prostate cancer? Urology. 2010;76:710-4.

15. Briganti A, Joniau S, Gontero P, Abdollah F, Passoni NM, Tombal B, et al. Identifying the best candidate for radical prostatectomy among patients with high-risk prostate cancer. Eur Urol. 2012;61:584-92.

16. Stephenson AJ, Kattan MW, Eastham JA, Bianco FJ Jr, Yossepowitch 0, Vickers AJ, et al. Prostate cancerspecific mortality after radical prostatectomy for patients treated in the prostate-specific antigen era. J Clin Oncol. 2009;27:4300-5.

17. Ward JF, Slezak JM, Blute ML, Bergstralh EJ, Zincke H. Radical prostatectomy for clinically advanced (cT3) prostate cancer since the advent of prostatespecific antigen testing: 15-year outcome. BJU Int. 2005;95:751-6.

18. Yossepowitch 0, Eggener SE, Serio AM, Carver BS, Bianco FJ Jr, Scardino PT, et al. Secondary therapy, metastatic progression, and cancer-specific mortality in men with clinically high-risk prostate cancer treated with radical prostatectomy. Eur Urol. 2008:53:950-9.

19. Eggener SE, Scardino PT, Walsh PC, Han M, Partin AW, Trock BJ, et al. Predicting 15-year prostate cancer specific mortality after radical prostatectomy. J Urol. 2011;185:869-75.
20. Spahn M, Briganti A, Capitanio U, Kneitz B, Gontero P, Karnes JR, et al. European Multicenter Prostate Cancer Clinical and Translational Research Group. Outcome predictors of radical prostatectomy followed by adjuvant androgen deprivation in patients with clinical high risk prostate cancer and pT3 surgical margin positive disease. J Urol. 2012;188:84-90.

21. Zwergel U, Suttmann H, Schroeder T, Siemer S, Wullich B, Kamradt J, et al. Outcome of prostate cancer patients with initial PSA $>$ or $=20 \mathrm{ng} / \mathrm{ml}$ undergoing radical prostatectomy. Eur Urol. 2007;52:1058-65.

22. Djaladat H, Amini E, Xu W, Cai J, Daneshmand S, Lieskovsky G. Oncological Outcomes After Radical Prostatectomy for High-Risk Prostate Cancer Based on New Gleason Grouping System: A Validation Study From University of Southern California With 3,755 Cases. Prostate. 2017;77:743-8.

23. Pierorazio PM, Ross AE, Lin BM, Epstein JI, Han M, Walsh PC, et al. Preoperative characteristics of highGleason disease predictive of favourable pathological and clinical outcomes at radical prostatectomy. BJU Int. 2012;110:1122-8.

24. Sundi D, Wang VM, Pierorazio PM, Han M, Bivalacqua TJ, Ball MW, et al. Very-high-risk localized prostate cancer: definition and outcomes. Prostate Cancer Prostatic Dis. 2014;17:57-63.

25. Pompe RS, Karakiewicz PI, Tian Z, Mandel P, Steuber T, Schlomm T, et al. Oncologic and Functional Outcomes after Radical Prostatectomy for High or Very High Risk Prostate Cancer: European Validation of the Current NCCN@ Guideline. J Urol. 2017;198:354-61.

26. Sundi D, Tosoian JJ, Nyame YA, Alam R, Achim M, Reichard CA, et al. Outcomes of very high-risk prostate cancer after radical prostatectomy: Validation study from 3 centers. Cancer. 2019;125:391-7.

27. Narang AK, Gergis C, Robertson SP, He P, Ram AN, McNutt TR, et al. Very High-Risk Localized Prostate Cancer: Outcomes Following Definitive Radiation. Int J Radiat Oncol Biol Phys. 2016;94:254-62.

28. Kuban DA, Levy LB, Cheung MR, Lee AK, Choi S, Frank $S$, et al. Long-term failure patterns and survival in a randomized dose-escalation trial for prostate cancer. Who dies of disease? Int J Radiat Oncol Biol Phys. 2011;79:1310-7.

29. Saad A, Goldstein J, Lawrence YR, Spieler B, Leibowitz-Amit R, Berger R, et al. Classifying high-risk versus very high-risk prostate cancer: is it relevant to outcomes of conformal radiotherapy and androgen deprivation? Radiat Oncol. 2017;12:5.

30. Cooperberg MR, Vickers AJ, Broering JM, Carroll PR. Comparative risk-adjusted mortality outcomes after primary surgery, radiotherapy, or androgendeprivation therapy for localized prostate cancer. Cancer. 2010;116:5226-34. Erratum in: Cancer. 2011;117:2825. 
31. Zelefsky MJ, Eastham JA, Cronin AM, Fuks Z, Zhang Z, Yamada $Y$, et al. Metastasis after radical prostatectomy or external beam radiotherapy for patients with clinically localized prostate cancer: a comparison of clinical cohorts adjusted for case mix. J Clin Oncol. 2010;28:1508-13.

32. Boorjian SA, Karnes RJ, Viterbo R, Rangel LJ, Bergstralh EJ, Horwitz EM, et al. Long-term survival after radical prostatectomy versus external-beam radiotherapy for patients with high-risk prostate cancer. Cancer. 2011;117:2883-91.

33. Kishan AU, Shaikh T, Wang PC, Reiter RE, Said J, Raghavan G, et al. Clinical Outcomes for Patients with Gleason Score 9-10 Prostate Adenocarcinoma Treated With Radiotherapy or Radical Prostatectomy: A Multi-institutional Comparative Analysis. Eur Urol. 2017;71:766-73.

34. Kalbasi A, Li J, Berman A, Swisher-McClure S, Smaldone M, Uzzo RG, et al. Dose-Escalated Irradiation and Overall Survival in Men With Nonmetastatic Prostate Cancer. JAMA Oncol. 2015;1:897-906.

35. Morris WJ, Tyldesley S, Rodda S, Halperin R, Pai H, McKenzie M, et al. Androgen Suppression Combined with Elective Nodal and Dose Escalated Radiation Therapy (the ASCENDE-RT Trial): An Analysis of Survival Endpoints for a Randomized Trial Comparing a Low-Dose-Rate Brachytherapy Boost to a Dose-Escalated External Beam Boost for High- and Intermediate-risk Prostate Cancer. Int J Radiat Oncol Biol Phys. 2017;98:275-85.

36. Ennis RD, Hu L, Ryemon SN, Lin J, Mazumdar M. Brachytherapy-Based Radiotherapy and Radical Prostatectomy Are Associated With Similar Survival in High-Risk Localized Prostate Cancer. J Clin Oncol. 2018;36:1192-8.

37. Berg S, Cole AP, Krimphove MJ, Nabi J, Marchese M, Lipsitz SR, et al. Comparative Effectiveness of Radical Prostatectomy Versus External Beam Radiation Therapy Plus Brachytherapy in Patients with High-risk Localized Prostate Cancer. Eur Urol. 2019;75:552-5.

38. Tilki D, Chen $\mathrm{MH}$, Wu J, Huland $H$, Graefen $M$, Braccioforte M, et al. Surgery vs Radiotherapy in the Management of Biopsy Gleason Score 9-10 Prostate Cancer and the Risk of Mortality. JAMA Oncol. 2018; [Epub ahead of print].

39. Lee DJ, Barocas DA, Zhao Z, Huang LC, Resnick MJ, Koyoma T, et al. Comparison of Patient-reported Outcomes After External Beam Radiation Therapy and Combined External Beam With Low-dose-rate Brachytherapy Boost in Men With Localized Prostate Cancer. Int J Radiat Oncol Biol Phys. 2018;102:116-26.

40. Monninkhof EM, van Loon JWL, van Vulpen $M$, Kerkmeijer LGW, Pos FJ, Haustermans K, et al. Standard whole prostate gland radiotherapy with and without lesion boost in prostate cancer: Toxicity in the FLAME randomized controlled trial. Radiother Oncol. 2018;127:74-80.
41. Sandler, H.M., et al. A phase III protocol of androgen suppression (AS) and 3DCRT/IMRT versus AS and 3DCRT/IMRT followed by chemotherapy (CT) with docetaxel and prednisone for localized, high-risk prostate cancer (RTOG 0521). Journal of Clinical Oncology, 2015. 33 (18_suppl): p. LBA5002LBA5002.

42. Barocas DA, Alvarez J, Resnick MJ, Koyama T, Hoffman KE, Tyson MD, et al. Association Between Radiation Therapy, Surgery, or Observation for Localized Prostate Cancer and Patient-Reported Outcomes After 3 Years. JAMA. 2017;317:1126-40. Erratum in: JAMA. 2017;317:2134.

43. Stranne J, Brasso K, Brennhovd B, Johansson E, Jäderling $F$, Kouri M, Lilleby W, Meidahl Petersen P, Mirtti T, Pettersson A, Rannikko A, Thellenberg C, Akre 0. SPCG-15: a prospective randomized study comparing primary radical prostatectomy and primary radiotherapy plus androgen deprivation therapy for locally advanced prostate cancer. Scand J Urol. 2018;52(5-6):313-20.

Correspondence address:

Andre Luis de Castro Abreu, MD USC Institute of Urology, Keck School of Medicine, University of Southern California 1441 Eastlake Ave, Suite 7416 Los Angeles, CA 90089, USA Fax: + 1323 865-0120

E-mail: andre.abreu@med.usc.edu

ARTICLE INFO

Saum Ghodoussipour https://orcid.org/0000-0001-8901-0210 Int Braz J Urol. 2019; 45: 428-34

Submitted for publication: April 20, 2019

Accepted after revision: May 05, 2019

Published as Ahead of Print: May 15, 2019 